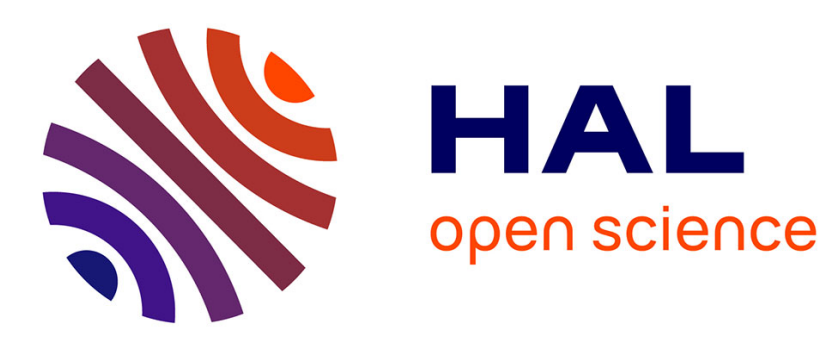

\title{
A Generic Benchmark for Power Market Analysis From Generation Mix To End-Users
}

Remy Rigo-Mariani, Keck Voon Ling, Jan Maciejowski, Keck Voon

\section{To cite this version:}

Remy Rigo-Mariani, Keck Voon Ling, Jan Maciejowski, Keck Voon. A Generic Benchmark for Power Market Analysis From Generation Mix To End-Users. 2018 Asian Conference on Energy, Power and Transportation Electrification (ACEPT), Oct 2018, Singapore, France. pp.1-8, 10.1109/ACEPT.2018.8610802 . hal-03519987

\section{HAL Id: hal-03519987 \\ https://hal.science/hal-03519987}

Submitted on 10 Jan 2022

HAL is a multi-disciplinary open access archive for the deposit and dissemination of scientific research documents, whether they are published or not. The documents may come from teaching and research institutions in France or abroad, or from public or private research centers.
L'archive ouverte pluridisciplinaire HAL, est destinée au dépôt et à la diffusion de documents scientifiques de niveau recherche, publiés ou non, émanant des établissements d'enseignement et de recherche français ou étrangers, des laboratoires publics ou privés. 


\title{
A Generic Benchmark for Power Market Analysis From Generation Mix To End-Users
}

\author{
Remy Rigo-Mariani ${ }^{1}$, Keck Voon Ling ${ }^{2}$, Jan Maciejowski ${ }^{3}$ \\ 1 - Cambridge Centre for Advanced Research and Education in Singapore Ltd, 1 CREATE Way, Singapore \\ 2 - School of Electrical and Electronic Engineering Nanyang Technological University, 50 Nanyang Ave, Singapore \\ 3 - Department of Engineering, University of Cambridge, Cambridge CB2 1PZ, UK, and ERI@N, NTU, Singapore \\ remyrm@,ntu.edu.sg, EKVLING@,ntu.edu.sg,jmm@eng.cam.ac.uk
}

\begin{abstract}
This paper presents a benchmark to model power systems market mechanisms from the generation mix to the endusers. The objective is to develop a platform that can help solving long-term planning problems. The operation described here is the joined day-ahead (DA) clearing for the wholesale market and the individual optimal scheduling of end-users equipped with distributed solar generation and storage. The implemented methods lie on linear programming whose fast computation allows to consider the decentralized control of an important number of end-users. Several scenarios are investigated with different retail prices and $\mathrm{CO}_{2}$ mitigation policies as well as different sizes for the decentralized assets at the end-users' level
\end{abstract}

Keywords-Energy market, wholesale market, decentralized control, distributed storage, linear programming

\section{INTRODUCTION}

The increasing introduction of renewable energy sources in modern power systems allows to face the limitation of fossil fuels while reducing the greenhouse gases emissions. However, the reliability and safe management of existing grids might be impacted by the variability and uncertainties attached to such sources of energy, in particular wind and solar. Thus renewable integration requires additional flexibility in modern systems [1]. One of the identified options is the flexible demand on the end-users side thanks to electrical vehicles ("vehicle to grid" V2G applications) [2], home storage [3] or controllable loads [4]. In such a framework the number of controllable devices might increase significantly. Thus game theory based decentralized controls are often investigated in the litterature in order to implement compact and scalable algorithms while fulfilling possible privacy issues [5]. Typically, each end-user aims at minimizing its electricity bill while a retailer wants to maximize its profit (i.e. the tradeoff between selling to the endusers and buying in the wholesale market) [6] [7]. Also involved in the wholesale market are the generation companies whose objective is a profit maximization while considering the costs of energy production. At that level, long-term generation expansion planning problems address the issue of identifying the most adequate technology, expansion size, and timing for the power generation [8]. The obtained results strongly depend on the regulation policies and incentives set by the market operator or governmental authorities [9].

The authors acknowledge the support by the Singapore National Research Foundation under its Campus for Research Excellence And Technological Enterprise (CREATE) programme and its Energy NIC grant (NRF Award No.: NRF-ENIC-SERTD-SMES-NTUJTCI3C-2016). This research was also supported by the Cambridge Centre for Advanced Research in Energy Efficiency in Singa pore Ltd (CARES).

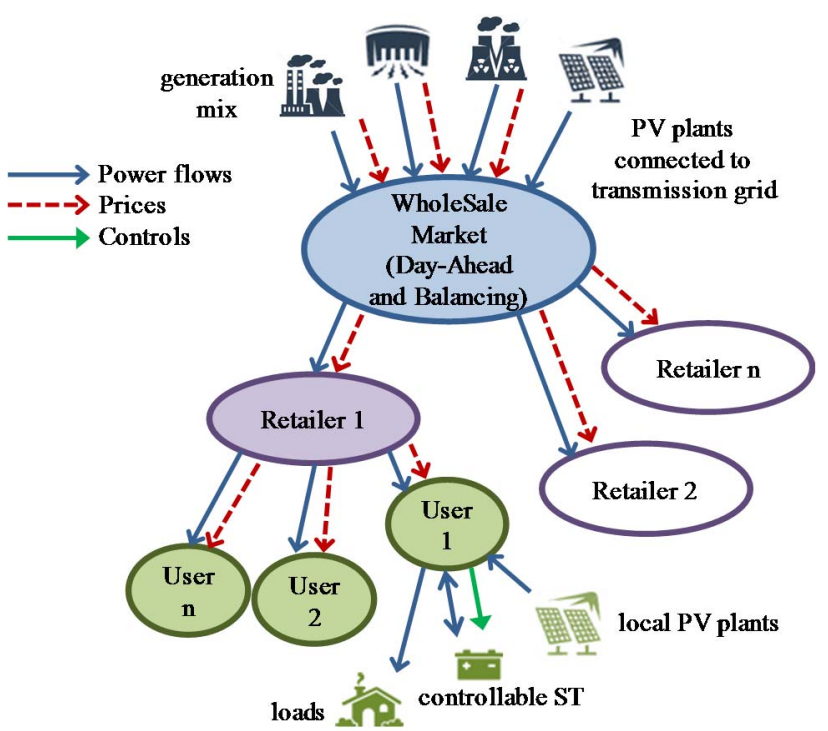

Fig. 1: Market architecture

In the literature, both end-user's energy management and wholesale market operations have been extensively investigated, independently, in the past decade. The objective of the study presented in this paper is an attempt to design a long-term planning tool that integrates all the major power systems actors, from the generation side to the end-users. The planning may refer to the optimization of generation mix, price policies or end-user's investments. Specifically, the first step which is presented here is the implementation of the day-ahead (DA) operations that allow to test different scenarios. The rest of the paper is organized as follow. Section II describes the test case with the market architecture and operations. Section III presents the optimization problems for both the DA market clearing and the optimal scheduling of the end-users' assets. Several case studies are then presented in Section IV before conclusions are given in Section V.

\section{MARKET DESIGN}

\section{A. Benchmark Architecture and Market Operations}

The work presented in this paper has been done in the context of the $\mathrm{C} 4 \mathrm{~T}$ project whose objective is carbon reduction in industrial/chemical activities. Jurong Island in Singapore is 
considered as a case study. Thus the market modeled as a benchmark here tends to represent the characteristics of the National Energy Market of Singapore (NEMS) [10]. The main difference with common markets encountered in Europe or North-America is the absence of distribution system operators due to the small scale of the national power systems. The architecture displays a typical pool market in which both generation companies and retailers bid to sale or purchase energy. On the generation side, photovoltaic (PV) plants directly connected to the transmissions system bid at a null price. On the consumption side, retailers buy at a variable price in the wholesale market and are subjected to regulated flat prices when providing energy to the end-users (Fig. 1). In the considered benchmark those end-users also own local PV plants as well as storage systems that can provide flexibility to the overall system. The considered architecture is associated to a two settlements wholesale markets with a day-ahead scheduling and balancing mechanism in real time [10] [11] in which the demand consists in the aggregation of different retailers' load. In the paper only DA operations are represented with the power system operator that clears the market for the next day at an hourly time step. The objective is to supply the predicted load with a minimum overall cost while fulfilling operating constraints and reserve requirements. It is commonly done while running security constrained unit commitment (UC) similarly to [12]. Note that nodal pricing is considered in Singapore with the fulfillment of the grid congestion constraints [13]. Here, network topology and congestion constraints are not considered and every buyers/sellers are subjected to a common marginal clearing price (MCP).

\section{B. End-Users in DA Market}

The contribution here is to investigate the involvement of end-users in the DA market thought the retailer's price policy. Three approaches can be found in the literature to addresses that type of problems while neglecting the wholesale market level. First, the problem can be considered as a bi-level optimization. On one side, the end-users receive prices signals from the aggregating entity (e.g. retailer) and minimize their electrical bill. On the other, the utility player tries to maximizes its profit that depends on the purchase price of energy multiplied by the aggregated load and on its own retail prices. (i.e. profit of selling energy). In most cases retail price profiles are generated using evolutionary methods while the end-users optimal scheduling is deterministic, for generic prosumers in [6] or EV parking lots in [2]. Another approach consists in using a Mathematical formulation with equilibrium constraints (MPEC). The equilibrium existence is usually proven and the bi-level optimization is rewritten as a single problem following the Karush-Kuhn-Tucker conditions [14] [15].

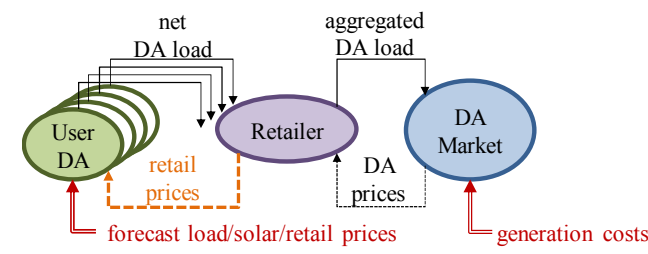

Fig. 2: DA Market with end-users's scheduling
The last method, which is considered here, performs successive retail price updates with the end-users that reschedule their load profile at each iteration (Fig. 2). The main shortcoming is that the convergence is not ensured. However, that approach is not computational intensive, easily scalable and has already been proven efficient for the decentralized control of distributed storage devices [16] [17].

\section{Consumption Profiles and Generation Mix}

In the DA market, each retailer buys energy on behalf of its customers while aggregating their individual load. Different consumption profiles are considered here in order to emulate the load of various types of users (Fig. 3a). The residential customers display moderate load levels during the day with a peak power in the evening. The commercial buildings are associated with day/night variations related to the opening hours. The industrial processes correspond to small deviations around a reference power, usually higher that other consumers' load level. Here, a set of different profiles are generated with random peak values and deviations around typical patterns 1500 residential, 10 commercial and 4 industrial. That pool of customers corresponds to a single retailer assumed to be representative of $1 / 1000$ of the total consumption from the wholesale market point of view. Fig. $3 b$ displays the aggregated day-ahead load that corresponds to the overall amount of energy traded in the DA market. Compared to the representative Singaporean load profile, the aggregated consumption simulated here shows a significant difference between the base load and the peak power at $5.9 \mathrm{GW}$. As it will be furtherly seen, that would require to start an important numbers of units along the day resulting in higher costs. Associated to its predicted consumption profile, each end-user also owns and controls local assets with PV panels and storage. Those devices are sized depending on each user's peak load level (different configurations will be investigated). On the generation side a set of 250 units is modeled with diverse resources from renewables (i.e. solar and hydro) to fossil fueled generators (i.e. coal, gas, oil). The units are emulated with random capacities, costs, minimum operating points and ramping limits around typical values for each technology. The "merit order curve" in Fig. 4 displays the cumulated capacities of all the units ranked from the lowest short-term marginal cost to the highest [18]. With less than $1 \%$ of the installed capacity the solar contribution is marginal. Note that the clearing price at the maximum load level is $67 \$ / \mathrm{MWh}$ with the most expensive gas unit in operation to meet $6 \mathrm{GW}$.
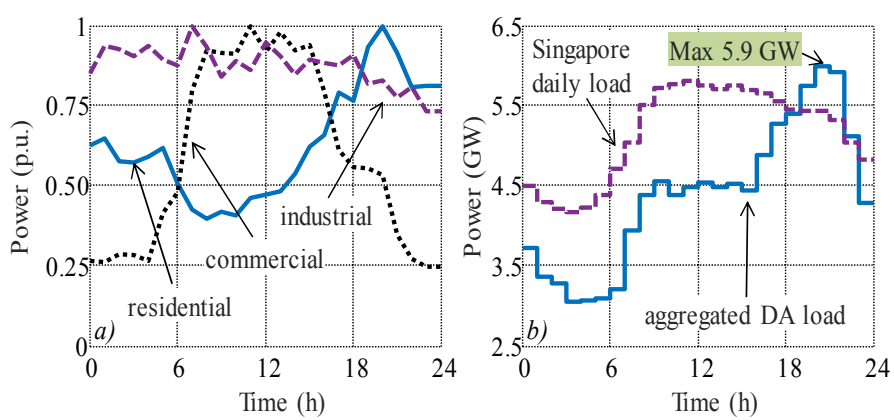

Fig. 3: Consumption profiles - a) individual users - b) aggregated load 


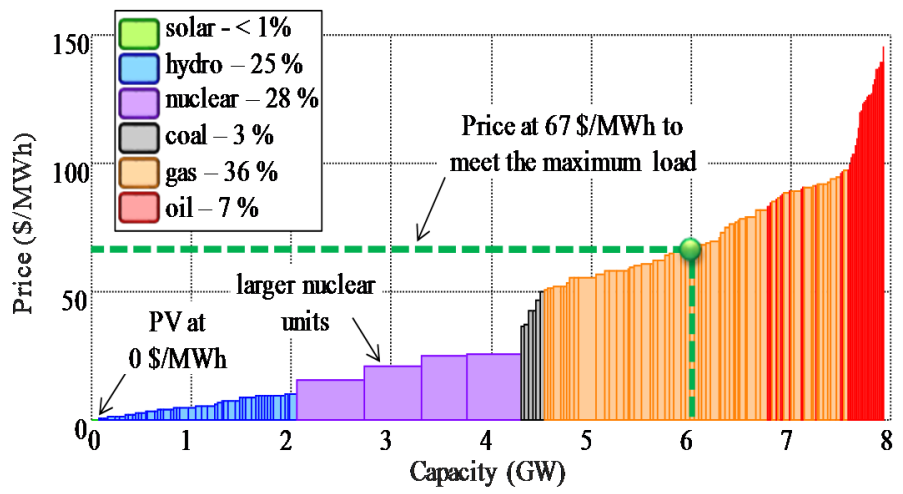

Fig. 4: Merit order curve of the simulated pool of generators

\section{MATHEMATIC FORMULATIONS}

This section describes the DA operations with the market clearing and the scheduling of the end-users' controllable assets. The retailer may also make decisions in the DA phase depending on the price policy. Different cases will be considered in the next section.

\section{A. Day-Ahead Market Clearing}

\section{1) Day-Ahead Unit Commitment}

As already mentioned, the DA market clearing relies on a unit commitment whose objective is to supply the load with a minimum cost and while fulfilling a set of system constraints. In the literature, that class of problems is commonly addressed using Mixed Integer Linear Programming (MILP) with a piecewise linearization of the generation costs [19]. However, the introduction of binaries (e.g. on/off status of the units) may lead to prohibitive computational times when great numbers of generators are considered. A linear approximation derived from [20] is implemented here with two continuous variables between 0 and $1\left(P_{g, t}^{O}\right.$ and $\left.P_{g, t}^{l}\right)$ along with traditional up/down reserves contribution $P_{g, t}^{R U}$ and $P_{g, t}^{R D}$ of each unit $g$ at time $t$ (Fig. 5). The operation of the units within their bounds $P_{g}^{\min }$ and $P_{g}^{\max }$ is ensured with constraint (1) while (2) shows that the generator has to be started before producing power and reserve below the upper limit. Constraints (3) allows to identify the start-up $S U_{g, t}$ of unit $g$ at time $t$.

$$
\begin{aligned}
& P_{g, t}^{G}=P_{g, t}^{0} \times P_{g}^{\text {min }}+P_{g, t}^{1} \times\left(P_{g}^{G m a x}-P_{g}^{G m i n}\right) \\
& P_{g, t}^{1}+\frac{P_{g, t}^{R U}}{P_{g}^{\text {Gmax }}-P_{g}^{\text {Gmin }}} \leq P_{g, t}^{0} \\
& P_{g, t}^{1}-P_{g, t-1}^{1} \leq S U_{g, t}
\end{aligned}
$$

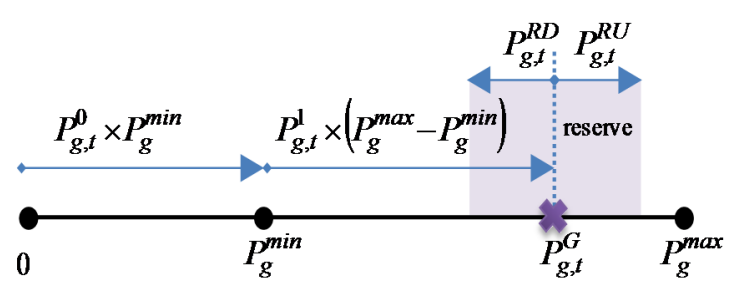

Fig. 5: Linear approximation of unit operation
TABLE I NOMENCLATURE FOR DA MARKET

\begin{tabular}{llc}
\hline Sets & & \\
$g \in G$ & set of units & - \\
$t \in T$ & set of time steps & - \\
Variables & & \\
$P_{g, t}^{G}$ & Power generated by unit $g$ at time $t$ & $\mathrm{MW}$ \\
$P_{g, t}^{O}, P_{g, t}^{I}$ & start/operation of unit $g$ at time $t[0,1]$ & - \\
$P_{g, t}^{R U}, P_{g, t}^{R D}$ & up/down reserve of unit $g$ at time $t$ & $\mathrm{MW}$ \\
$S U_{g, t}$ & start-up of unit $\mathrm{g}$ at time $\mathrm{t}$ in $[0,1]$ & $\mathrm{MW}$ \\
$P_{t}^{R U / G}$ & maximum unit output time $t$ & $\mathrm{MW}$ \\
Parameters & & \\
$P_{t}^{L}$ & day-ahead load at time $t$ & $\mathrm{MW}$ \\
$P_{g}^{G \min }, P_{g}^{G m a x}$ & min/max operating points of units $g$ & $\mathrm{MW}$ \\
$P_{g}^{R U m a x}, P_{g}^{R D m a x}$ & maximum up/down reserve of unit $g$ & - \\
$C_{g}^{0}$ & start-up cost of unit $g$ & $\$$ \\
$C_{g}$ & operating cost of unit $g$ at time $t$ & $\$ / \mathrm{MWh}$ \\
$C_{g, t}^{R U}, C_{g, t}^{R D}$ & operating cost of unit $g$ at time $t$ & $\$ / \mathrm{MWh}$ \\
$\alpha^{R}$ & load forecast error & $\%$ \\
\hline
\end{tabular}

Compared to conventional UC formulations [19], the problem is simplified here: there is no introduction of up/down times or ramp constraints and, more important, the grid topology is not considered thought power flows constraints. However, a specific attention is attached to the spinning reserve contributions with the up and down costs $\left(C_{g}^{R U}, C_{g}^{R D}\right)$ and units that have to operate within specified bounds $\left(P_{g}^{R U \max }, P_{g}^{R D \max }\right)(4)$. For the up-reserve requirements at time $t$, the objective is to compensate the forecast error expressed in per cent $\left(\alpha^{R}\right)$ of the load to supply $P_{t}^{L}$. Also, the total amount of up-reserve should be able to compensate the loss of the biggest generator in operation while providing its generated power at time $t$ denoted $P_{t}^{R U / G}((5)$ and (6)). The down-reserve should only balance the forecast error (7) and the contribution of each unit should comply with the operating limit in in case of low operating point (8).

$$
\begin{aligned}
& 0 \leq P_{g, t}^{R U}, P_{g, t}^{R D} \leq P_{g}^{R U \max }, P_{g}^{R D \max } \\
& \sum_{g \in G} P_{g, t}^{R U} \geq\left(1-\alpha^{R}\right) \times P_{t}^{L}+P_{t}^{R U / G} \\
& P_{t}^{R U / G} \geq P_{g, t}^{G} \forall g \in G \\
& \sum_{g \in G} P_{g, t}^{R D} \geq\left(1-\alpha^{R}\right) \times P_{t}^{L} \\
& P_{g, t}^{R D} \leq P_{g, t}^{1} \times\left(P_{g}^{G m a x}-P_{g}^{G m i n}\right)
\end{aligned}
$$

The power balance is ensured with (9) and the objective function is finally computed following (10) with startup, energy and reserve cost - $C_{g}^{0}, C_{g}, C_{g}^{R U}, C_{g}^{R D}$ - of each unit $g$. Note that the hourly time step is not included in the equation. Table I gives a list of the used symbols for the DA market clearing. The 
problem is formulated in MATLAB using YALMIP [21] and solved with CPLEX 12.7.1 (16 threads in parallel, 16 GB RAM, $3.2 \mathrm{GHz}$ processor).

$\sum_{t \in G} P_{g, t}^{G}=P_{t}^{L} \forall t \in G$

obj: $\quad \sum_{t \in T} \sum_{g \in G}\left(\begin{array}{c}P_{g, t}^{G} \times C_{g}+S U_{g, t} \times C_{g}^{0} \cdots \\ \ldots+P_{g, t}^{R U} \times C_{g, t}^{R U}+P_{g, t}^{R D} \times C_{g, t}^{R D}\end{array}\right)$

\section{2) Computation of Up/Down Reserve Costs}

In this study, the reserve costs of each unit are not necessary entered as parameters in the UC solving. The approach introduced in [22] [23] is considered instead. The idea is to value the potential benefit a generator would get while contributing to the reserve. In particular, that benefit depends on the market clearing price $\lambda_{t}^{E}$ which is computed as the lagrangian of the power balance constraint (9). Obviously, that energy price will be different at each time step with different load levels and operating units. Consequently, the reserve costs of each unit will vary all along the day with their operating point. In practice the UC is run in an iterative process. The unit reserve costs are initialized equal to the unit operating costs and are then updated at each iteration using the UC outputs $\left(\lambda_{t}^{E}, P_{g, t}^{R U}\right.$ and $P_{g, t}^{R D}$ ) and following (11). The convergence is assumed to be reached when there is no difference in the units schedules between two iterations. Prices profiles for reserve up $\lambda_{t}^{R U}$ and down $\lambda_{t}^{R D}$ are the lagrangian of (5) and (7).

$$
\left[\begin{array}{l}
C_{g, t}^{R U} \\
C_{g, t}^{R D}
\end{array}\right]=\left\{\begin{array}{l}
{\left[\begin{array}{c}
\lambda_{t}^{E}-C_{g} \\
0
\end{array}\right], \text { if } \lambda_{t}^{E} \geq C_{g}} \\
{\left[\begin{array}{c}
\left(C_{g}-\lambda_{t}^{E}\right) \times \frac{P_{g}^{G m i n}}{P_{g, t}^{R U}} \\
\left(C_{g}-\lambda_{t}^{E}\right) \times \frac{P_{g}^{G m i n}-P_{g, t}^{R U}}{P_{g, t}^{R U}}
\end{array}\right], \text { otherwise }}
\end{array}\right.
$$

TABLE II NOMENCLATURE FOR DA SCHEDULE OF END-USER $n$

\begin{tabular}{llc}
\hline Sets & & \\
$t \in T$ & set of time steps & \\
Variables & & \\
$P_{n, t}^{S T+}, P_{n, t}^{S T-}$ & storage charge/discharge at time $t$ & $\mathrm{MW}$ \\
$P_{n}^{P}$ & peak power & $\mathrm{MW}$ \\
$S O C_{n, t}$ & State of charge of user $n$ at time $t$ & $\%$ \\
Parameters & & \\
$P_{n, t}^{l}$ & day-ahead load of user $n$ at time $t$ & $\mathrm{MW}$ \\
$P_{n, t}^{p v}$ & day-ahead PV of user $n$ at time $t$ & $\mathrm{MW}$ \\
$\lambda_{t}^{R}$ & retail price at time $t$ & $\$ / \mathrm{MWh}$ \\
$\lambda^{P}$ & price for the peak power & $\$ / \mathrm{MW}$ \\
$E_{n}^{S T}, P_{n}^{S T m a x}$ & storage capacity and rated power & $\mathrm{MW}(\mathrm{h})$ \\
$S O C^{\min }, S O C^{\max }$ & load forecast error & $\%$ \\
$\eta^{S T}$ & storage efficiency & $\%$ \\
\hline
\end{tabular}

\section{B. Day-Ahead Scheduling of End-Users}

In day-ahead, end-users might be willing to schedule their actions in order to minimize their electrical bill depending on the prices given by their power supplier (i.e. retailer). This scheduling lies on a DA model predictive control that considers the forecasts for the local consumption $P_{n, t}^{l}$ of user $n$ and its local solar generation $P_{n, t}^{p v}$. At the end-user's level, the degree of freedom comes from the local energy storage asset with a given capacity $E_{n}^{S T}$. Thus the first decision variables of the scheduling problem are the charge/discharge powers $P_{n, t}^{S T+}, P_{n, t}^{S T-}$ within their bounds $((12))$ as it is commonly done to consider the efficiency $\eta^{S T}$ when computing the state of charge at each time step $S O C_{n, t}((13))$ [24]. The $S O C_{n, t}$ has to remain within acceptable limits (typically $S O C^{\min }=0$ and $S O C^{\max }=100 \%$ and should return to its initial value at the end of the day (typically $50 \%$ ) (14). Additional constraints are added with (15) in order to limit the use of the storage device to a single cycle per day [25]. Time dependent energy prices $\lambda_{t}^{R}$ as well as a penalty for the peak power $\lambda^{P}$ are considered. A variable $P_{n}^{P}$ is introduced in order to track the peak power along the day with (16) and (17) ensures that the peak power after scheduling is no higher than the maximum net load with no control (i.e. base case). The objective function is finally computed following (18).

$$
\begin{aligned}
& 0 \leq P_{n, t}^{S T+}, P_{n, t}^{S T-} \leq P_{n}^{S T m a x} \\
& S O C_{n, t}=S O C_{n, t-1}+\left(\eta^{S T} \times P_{n, t}^{S T+}-\frac{P_{n, t}^{S T-}}{\eta^{S T}}\right) \times \frac{100}{E_{n}^{S T}} \\
& S O C^{\text {min }} \leq S O C_{t} \leq S O C^{\max } \text { and } S O C_{t=T}=S O C_{t=0} \\
& \sum_{t \in T} \frac{P_{n, t}^{S T-}}{\eta^{S T}}=\sum_{t \in T} \eta^{S T} \times P_{n, t}^{S T+}=\frac{E_{n}^{S T}}{100}\left(S O C^{\max }-S O C^{\min }\right) \\
& P_{n}^{P} \geq P_{n, t}^{l}-P_{n, t}^{p v}-P_{n, t}^{S T-}+P_{n, t}^{S T+} \forall t \in T \\
& P_{n}^{P} \leq \max \left(P_{n, t}^{l}-P_{n, t}^{p v}\right)
\end{aligned}
$$$$
\text { obj: } P_{n}^{P} \times \lambda^{R}+\sum_{t \in T}\left(P_{n, t}^{l}-P_{n, t}^{p v}-P_{n, t}^{S T-}+P_{n, t}^{S T+}\right) \times \lambda_{t}^{R}
$$

\section{CASE STUdies}

\section{A. DA Market and Impact of Reserve Requirements}

A first set of simulations is run while clearing the day-ahead market. Fig. $6 a$ displays the results obtained when running the DA unit commitment in order to meet the aggregated load without considering the local generation on the end-users' side. The PV generation is marginal, the other cheapest resources (i.e. hydro and nuclear) supply the bulk energy wile more expensive units are start-up to feed the peak. In particular, the number of running units almost doubles in the middle of the day (Fig. 6c). The assumption for the base case scenario (denoted R0) is to fulfill the reserve constraints with an expected prediction error $\alpha^{R}=20 \%$. As observed on Fig. $6 b$, the 
requirements for the up-reserve are more important due to necessity to cover additional generation in case of failure of the largest operating unit. At the beginning of the day that upreserve is provided by the hydro generators and then mostly with the gas units which also display high ramping capacities. Concerning the down-reserve, it is mostly supplied by the hydro generation except when the contribution of gas fueled units becomes more significant at peak times. The fulfillment of those reserve constraints then requires to run more units than it would be necessary to only meet the peak power. Consequently, as seen on Fig. $6 d$, the marginal price of energy displays strong variations with a spike at $125 \$ / \mathrm{MWh}$ much higher than the maximum MCP of $67 \$ / M W h$ discussed in Section II.C (Fig. 4). Also note that the price for the down reserve is null with the cost computation in (11) and only infra marginal units are running. Table III gives a cost analysis for different reserve requirements. R1 also corresponds to $\alpha^{R}=20 \%$ but with no constraint to compensate the loss of the largest unit. Then R2 and $\mathbf{R 3}$ decrease $\alpha^{R}$ respectively to $10 \%$ and $5 \%$. Moving from $\mathbf{R 0}$ to R1 strongly reduce all the cost components as well as the peak price with a large amount of energy that does not need to be backed up. As expected the less the reserve needs are the closer the maximum price is from the theoretical MCP of 67 \$/MWh.
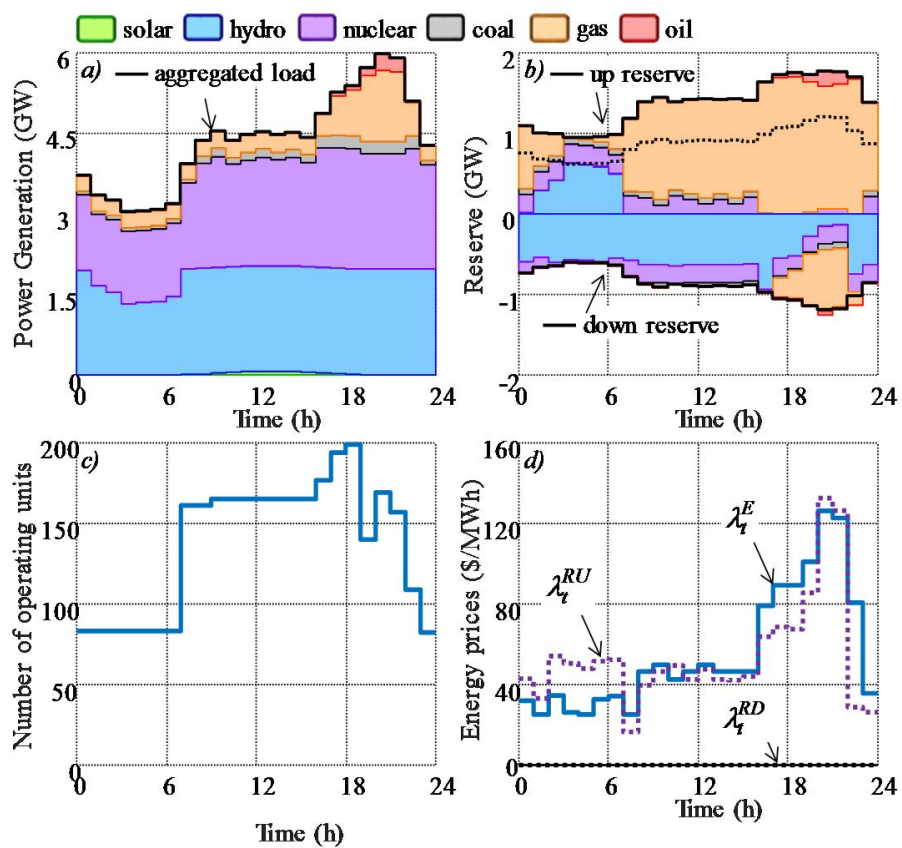

Fig. 6: Result for the base case scenario - a) generation mix - b) up/down reserve mix $-c$ ) operating units $-d$ ) energy prices

TABLE III GENERATION COSTS FOR DIFFERENT RESERVE REQUIREMENTS

\begin{tabular}{lcccc}
\hline Scenario & R0 & R1 & R2 & R3 \\
\hline Energy cost $(\mathrm{k} \$)$ & 2080 & 1900 & 1821 & 1785 \\
Reserve cost $(\mathrm{k} \$)$ & 507 & 137 & 45 & 15 \\
Start-up cost $(\mathrm{k} \$)$ & 113 & 117 & 103 & 103 \\
TOTAL $(\mathrm{k} \$)$ & 2700 & 2154 & 1969 & 1903 \\
Max price $(\$ \mathrm{MWh})$ & 125 & 87 & 83 & 69 \\
\hline
\end{tabular}

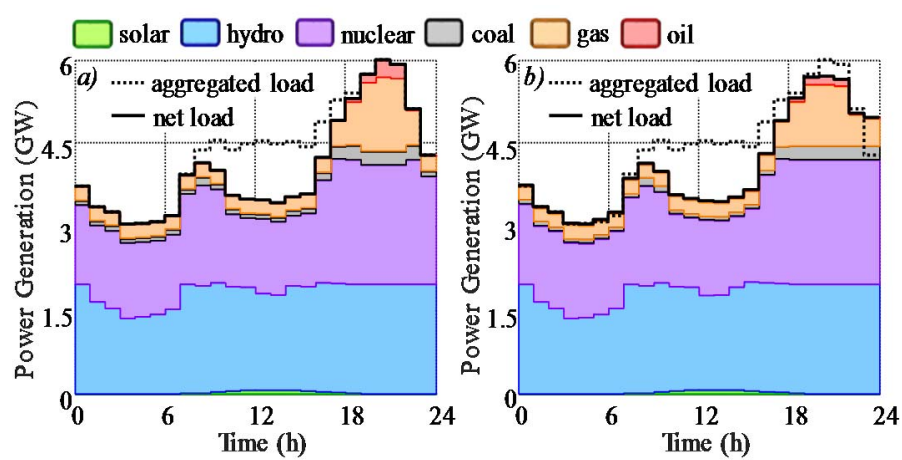

Fig. 7: Generation mix with end-users' net load -a) PV only - b) PV, storage and $\mathbf{P 1}$

\section{B. Different Retail Price Policies}

In the previous simulations, the aggregated DA load to supply consisted is the prediction of the consumption part on the end-users' side. In this subsection, the distributed assets are included in the DA scheduling and will have an impact on the global net load. For every customer, PV peak power and storage capacity both correspond to $20 \%$ of the user's peak load. At first, only the prediction for the decentralized solar generation is considered. The DA market is cleared and the net aggregated load in Fig. $7 a$ to follow displays a decrease during day hour compared to the base case (typical "duck curve" [26]). When the flexibility allowed by distributed storage devices is considered, the peak net load decrease by almost300 MW (from $5979 \mathrm{MW}$ to $5696 \mathrm{MW}$ ). The power profile remains unchanged the most part of the day compared to the case where only the decentralized PV is predicted. The storages discharge in the evening in order to lower the peak and are charged afterwards, resulting in a higher net load than in the base case scenario (Fig. $7 b$ ). This simulation is run according to the iterative process in Fig. 2. After the DA market optimization is performed, the retailer sets its price policy according to the day-ahead MCP $\lambda_{t}^{E}$. A first, the considered policy $\mathbf{P} \mathbf{1}$ consists in a flat retail price $\lambda_{t}^{R}$ equals to the mean value of $\lambda_{t}^{E}$ increased by $5 \%$ for the selling margin. The penalty for each end-users' peak load is set to the maximum MCP $\left(\lambda^{P}\right.$ in $\left.\$ / \mathrm{MW}\right)$. That price policy is then considered by every customer that adapt their scheduling accordingly to minimize their electrical bill. The DA market is run another time and considering the updated aggregated net load. In addition to the peak load reduction, the maximum day -ahead clearing price also decreases with a total cost of generation lowered by $13 \%$ compared to the base case scenario (i.e. R0 here) (Table IV). Other prices policies are then investigated. In $\mathbf{P 2}$ the retail energy prices $\lambda_{t}^{R}$ follows the day ahead MCP profile (increased by $5 \%$ ) while $\mathbf{P 3}$ considers a "time of use" rate consisting in four time slots of $6 \mathrm{~h}$ average of $\lambda_{t}^{E}$ (Fig. 8a). The simulation environment allows to find the global solution for the DA market that corresponds to a centralized control of the distributed assets. In this scenario denoted as $\mathbf{P} *$, the DA unit commitment is rewritten while introducing the controls for all the distributed storage as additional decision variables. Logically, the obtained solution displays the lowest peak prices and peak load when compared to the different prices policies for decentralized control (Table 
IV, Fig. 8a). P2 allows to reach the second best results while considering day ahead hourly prices sent to the end-users that can schedule their storage accordingly. However, the shortcoming of such a rate policy could lie in its lack of clarities and uncertainties for the customer as it is subject to change every day at an hourly time step. Thus time of use prices might offer a good alternative, provided that the rate levels along the day are appropriately designed to guarantee good performances on a representative period (i.e. from a couple of months to a year). The benchmark developed in this paper can be used to tune those prices as best as possible in a planning framework. In all the considered policies here a penalty for the end-users' daily peak power is introduced. Preliminary results showed bad performances when only energy prices are taken into account. Especially, in case of flat rates there would be no point in performing an optimal scheduling with no peak power price (in \$/MW). Indeed, in such a scenario shifting any amount of energy in time thanks to storage systems would results in no benefit. The end-users' bill would even be greater considering the storage losses. Prices policies with peak power price usually refer to heavy customers with a penalty depending on the monthly peak. That should then be generalized if distributed storage tend to be installed in different type of end-user's facilities.
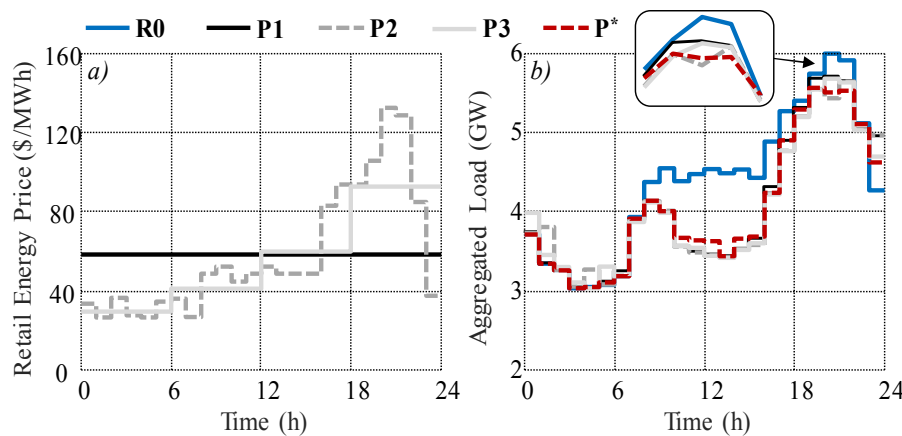

Fig. 8: Retail prices policies $-a$ ) energy rates - b) aggregated net load

TABLE IV GENERATION COSTS FOR DIFFERENT RETAIL PRICE POLICIES

\begin{tabular}{lcccc}
\hline Scenario & P1 & P2 & P3 & P $^{*}$ \\
\hline Energy cost $(\mathrm{k} \$)$ & 1810 & 1778 & 1778 & 1773 \\
Reserve cost $(\mathrm{k} \$)$ & 374 & 375 & 384 & 304 \\
Start-up cost $(\mathrm{k} \$)$ & 109 & 106 & 109 & 104 \\
TOTAL $(\mathrm{k} \$)$ & 2294 & 2259 & 2271 & 2181 \\
Max price $(\$ / \mathrm{MWh})$ & 97 & 91 & 96 & 83 \\
Peak Load $(\mathrm{MW})$ & 5696 & 5639 & 5686 & 5559 \\
\hline
\end{tabular}

TABLE V GENERATION COSTS FOR DIFFERENT SIZES OF DISTRIBUTED ASSETS

\begin{tabular}{lcccc}
\hline PV size (\%) & $\mathbf{2 0}$ & $\mathbf{4 0}$ & $\mathbf{6 0}$ & $\mathbf{6 0}$ \\
ST size (\%) & $\mathbf{2 0}$ & $\mathbf{4 0}$ & $\mathbf{6 0}$ & $\mathbf{1 0 0}$ \\
\hline Energy cost $(\mathrm{k} \$)$ & 1778 & 1584 & 1411 & 1427 \\
Reserve cost $(\mathrm{k} \$)$ & 375 & 272 & 233 & 178 \\
Start-up cost $(\mathrm{k} \$)$ & 106 & 114 & 176 & 128 \\
TOTAL $(\mathrm{k} \$)$ & 2259 & 1972 & 1820 & 1735 \\
Max price $(\$ / \mathrm{MWh})$ & 91 & 87 & 87 & 75 \\
Peak Load $(\mathrm{MW})$ & 5639 & 5440 & 5280 & 5055 \\
\hline
\end{tabular}

\section{Different Sizes of Decentralized Assets}

In the next set of simulations, different sizes for the distributed assets (i.e. end-users' PV and storage) are investigated. As in the previous subsection, the reserve requirements corresponding to the base case scenario $\mathbf{R 0}$ are considered as well as the retail price policy P3. For each customer, those sizes are expressed in per cent of the peak load. As expected and shown in Table $\mathrm{V}$, the total generation strongly decreased with greater sizes for the distributed assets. However, it is worth noticing that the start-up cost increases for significant amount of distributed PV. Indeed, with a "deeper duck curve", thermal units are shut down when the solar generation ramps up to be further switch on again at the end of the afternoon, resulting in a higher cost. PV penetration has a direct impact on the energy costs with a reduced need of costlier generation. Distributed storage systems reduce the cost when avoiding to startup more expensive units to supply the peak. Thus integrating such technologies would make more sense in a context of diverse generation mix with a set of units displaying a wider range of operating cost. The methodology implemented in this paper could then be used to estimate the best size of the distributed assets depending on the energy context (i.e. energy mix and price policy).

\section{Carbon Tax ans Carbon Limits}

The final simulations presented in this subsection aims at integrating $\mathrm{CO}_{2}$ emissions in the developed benchmark. The objective here is to find a tradeoff between the cost of generation and the corresponding carbon emissions. Biobjective optimizations and Pareto optimality are sometimes investigated in the literature [27] but the most widely used approach consists in setting a price for the produced $\mathrm{CO}_{2}$, i.e. a carbon tax denoted $\mathrm{C}^{\mathrm{CO} 2}$ here [28]. That approach implies to modify the formulation of the objective function (10) for the DA unit commitment following (19) with the introduction of the $\mathrm{CO}_{2}$ emissions for each generators $\beta_{t}^{C O 2}$. Those carbon factors are derived from [29] for the coal, gas and oil fueled units while solar, nuclear and hydro generators are not affected.

$o b j \leftarrow o b j+\sum_{t \in T} \sum_{g \in G} P_{g, t}^{G} \times \beta_{g}^{C O 2} \times C^{C O 2}$

At first, the previously studied scenario R0 is considered for the DA market scheduling and the minimization of the generation costs $(2700 \mathrm{k} \$$ in that case). Carbon emissions and costs are then computed with 9007 tons resulting in an increase of $7 \%$ of the total cost with $C^{C O 2}$ set to $20 \$ /$ ton (Table VI).

TABLE VI GENERATION/CO $\mathrm{CO}_{2}$ COSTS FOR DIFFERENT CARBON TAXES

\begin{tabular}{lcccc}
\hline Scenario & $\mathbf{R 0}$ & $\mathbf{R 0}^{\mathbf{C 0 2}}$ & $\mathbf{R 0}^{\mathbf{C 0 2}}$ & $\mathbf{P 3}^{\mathbf{C 0 2}}$ \\
$\mathbf{C}^{\mathbf{C O 2}}$ (in \$/ton) & $\mathbf{2 0}$ & $\mathbf{2 0}$ & $\mathbf{4 0}$ & $\mathbf{4 0}$ \\
\hline Generation Cost $(\mathrm{k} \$)$ & 2700 & 3008 & 3077 & 2728 \\
$\mathrm{CO}_{2}$ emissions (tons) & 9007 & 8295 & 7847 & 6665 \\
$\mathrm{CO}_{2}$ cost $(\mathrm{k} \$)$ & 181 & 165 & 313 & 266 \\
$\mathrm{TOTAL}(\mathrm{k} \$)$ & 2881 & 3173 & 3390 & 2993 \\
\hline
\end{tabular}



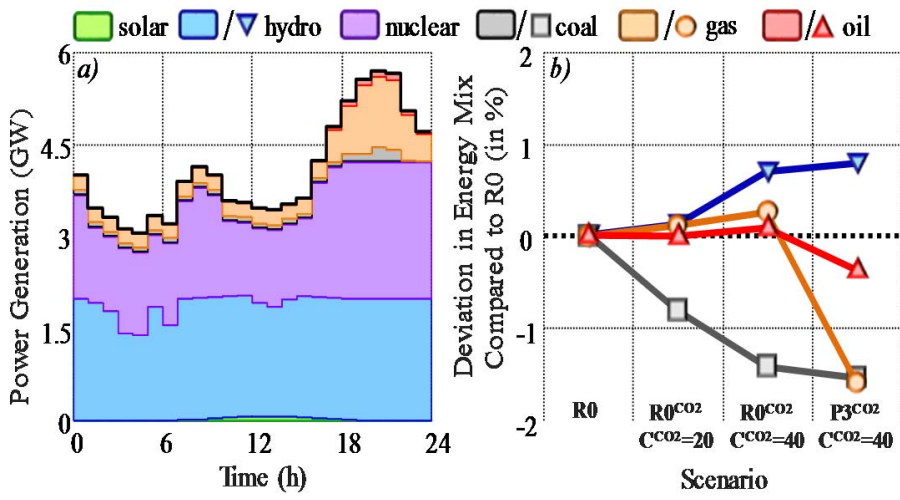

Fig. 9: Introduction of carbon tax - a) results for $\mathbf{P 3}^{\mathbf{C O} 2}-$ b) energy mix deviations for different scenarios

When the carbon cost is included in the DA objective function the obtained results displayed more significant generation costs with a reduced amount of generated $\mathrm{CO}_{2}$ (scenario denoted as $\mathbf{R 0}^{\mathbf{C O 2}}$ ). Obviously a greater carbon tax tends to increase all the costs while the DA unit commitment tries to lower the emissions as much as possible. The scenario P3 is run while considering the optimal DA scheduling of endusers (PV and ST at $20 \%$ of the peak load) and the aggregated net load is sent back to the DA market schedule with carbon tax (scenario $\mathbf{P 3}^{\mathrm{CO} 2}$ ). As previously, those distributed assets allow a reduction of the generation cost but that also actively participate to a strong reduction of the emitted $\mathrm{CO}_{2}$ for the simulated day. Fig. $9 a$ displays the generation mix for the scenario $\mathbf{P 3}^{\mathbf{C O} 2}$ with a slightly reduced use of the coal fueled unit compared to the a case with no carbon tax (Fig. 7b). Indeed, as expected the need to reduce the emissions to avoid higher costs leads to a decreased use of the dirties units (i.e. coal) while the hydro generation tends to increase. Also note in that the oil and gas generation is also increased as those fossil fueled generators are "cleaner" than the coal ones - Fig. $9 a$ with results expressed in \%, deviations $+/$ - compared to the base case generation mix R0.

Another method to consider carbon penalties is the introduction of emissions limits in the DA unit commitment [30]. Thus an arbitrary maximum quantity $Q^{\mathrm{CO} 2}$ (in tons) is considered as an additional constraint in the original scheduling targeting a cost minimization ((20)). As displayed in Table VII the generations costs significantly increase when the $\mathrm{CO} 2$ constraints becomes tighter until no convergence is possible (e.g. 4500 tons limitation here).

$$
\sum_{t \in T} \sum_{g \in G} P_{g, t}^{G} \times \beta_{g}^{C O 2} \leq Q^{C O 2}
$$

TABLE VII GENERATION/CO ${ }_{2}$ COSTS FOR DIFFERENT CARBON LIMITS

\begin{tabular}{lcccc}
\hline Scenario & $\mathbf{R 0}^{\mathbf{C O 2}}$ & $\mathbf{R 0}^{\mathbf{C} 02}$ & $\mathbf{R 0}^{\mathbf{C} 02}$ & $\mathbf{R 0}^{\mathbf{C} 02}$ \\
$\mathbf{Q}^{\mathbf{C O 2}}$ (in tons) & $\mathbf{7 5 0 0}$ & $\mathbf{6 0 0 0}^{2}$ & $\mathbf{5 5 0 0}$ & $\mathbf{4 5 0 0}$ \\
\hline Generation Cost $(\mathrm{k} \$)$ & 3158 & 5779 & 6033 & N.A. \\
\hline
\end{tabular}

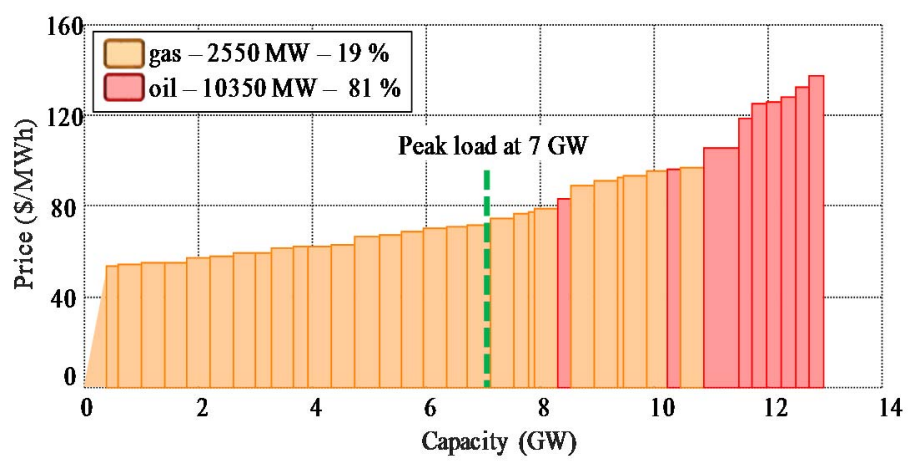

Fig. 10: "Guessed" merit order curve for the energy mix in Singapore

\section{E. Discussions on the Singaporean Context}

As already mentioned the work presented in this paper has been led in the framework of a wider project taking place in Singapore. The national power grid displays a high reliability level as well as the lowest losses in the world (2\% [31]) with low impedance underground cables and short distances. Concerning the generation mix, there is no diversity with around $10 \mathrm{GW}$ of gas fueled units (i.e. combined cycle gas turbine, open cycle, cogeneration) and $3 \mathrm{GW}$ of oil steam turbine. In 2016 more than $97 \%$ of the electricity was generated with natural gas [1]. Today renewable remains marginal with a little more than $100 \mathrm{MW}$ of PV panels connected. The opportunities for other renewables sources might be limited. There is no geothermal potential and the wind resource is too scarce for onshore installations. Offshore applications might be a better option but their implementation could prove challenging with the marine transport. Biomass might be considered but would require the importation of significant amount of waste due to the low level of agricultural activities nationwide. Fig. 10 is an attempted to plot the expected merit order curve for the Singaporean generation mix and based on the few available information. The first point to notice is the excess of installed capacity that is almost the double of the maximum registered peak load ( $13 \mathrm{GW}$ versus $7 \mathrm{GW})$. In practice that excess allows the national grid to work with a $30 \%$ reserve constraints. Another interesting aspect is that the absence of diversity in the mix might mitigate the improvements provided by the introduction of decentralized assets (i.e. renewable and storage) with homogeneous cost/emissions for all the unit. Also the units' sizes are relatively important compared to the load level. With 400MW combined cycle units, it means that significant amount of renewable should be introduce to compensate a single generator and the subsequent improvement will not be important (in terms of cost or emissions).

\section{CONCLUSIONS}

This paper successfully implemented a generic benchmark to represent some base mechanisms in power system.: market clearing, retail pricing, end-user scheduling. Day-ahead operations have been simulated using simplified algorithms that allowed to test a wide range of scenarios with more than a thousand different end-users. The outcomes of the considered case studies highlighted the necessity to appropriately design 
prices (e.g. retail) or incentives (e.g. carbon tax) that will have an impact on the global system performances. Thus such a benchmark should further be integrated in a planning procedure that could jointly determine the most appropriate sizes for the distributed assets and the corresponding policies. Additional work may lead to the introduction of real-time market with balancing mechanisms. That would allow to establish different strategies on the end-users' side, which is still open to suggestions today.

\section{REFERENCES}

[1] M.I. Alizadeh, M. P. Moghaddam, N. Amjady, P. Siano, M. K. SheikhEl-Eslami, "Flexibility in future power systems with high renewable penetration: A review", Renewable and Sustainable Energy Reviews, Vol. 57, pp. 1186-1193, 2016.

[2] S. Aghajani, M. Kalantar, "A cooperative game theoretic analysis of electric vehicles parking lot in smart grid”, Energy, Vol. 137, pp 129-139, 2017.

[3] A. Mondal, S. Misra, M. S. Obaidat, "Distributed home energy management system with storage in smart grid using game theory", IEEE System Journal, Vol. 11, No 3, pp 1857-1866, 2017.

[4] N. Li, L. Chen, S. H. Low, "Optimal demand response based on utility maximization in power networks", IEEE Power and Energy Society General Meeting, Detroit, MI, United-States, July 2011.

[5] W. Saad, Z. Han, H. Vincent Poor, T. Başar, "Game-theoric methods for the smart grid”, IEEE Signal Processing Magazine, pp 86-105, 2012.

[6] L. Ma, N. Liu, J. Zhang, W. Tushar, C. Yuen, "Energy management for joint operation of CHP and PV prosumers inside a grid-connected microgrid: a game theoretic approach", IEEE Transactions on Industrial Informatics, Vol. 12, No 5, pp 1930-1942, 2016.

[7] T. Zhao, X. Pan, S. Yao, P. Wang, "Stackelberg game based energy and reserve management for a fast electric vehicle charging station", Energy Conversion Congress and Exposition (ECCE), Cincinnati, OH, UnitedStates, October 2017.

[8] N. Neshat, M.R. Amin-Naseri, "Cleaner power generation through market-driven generation expansion planning: an agent-based hybrid framework of game theory and particle swarm optimization", Journal of Cleaner Production, Vol. 105, pp 206-217, 2015.

[9] C. L. Prete, B. F. Hobbs, "A cooperative game theoretic analysis of incentives for microgrids in regulated electricity markets", Applied Energy, Vol. 169, pp 524-541, 2016.

[10] Singapore Energe Market Authority, "Introduction to the national electricity market of singapore", 2010. [online] www.ema.gov.sg

[11] PJM, "Energy and ancillary services, market operations", 2016. [online] www.pjm.com

[12] J. Wang, M. Shahidehpour, Z. Li, "Contingency-constrainted reserve requirments in joint energy and ancillary services auction", IEEE Transactions on Power Systems, Vol. 24, No 3, pp 1457-1468, 2009.

[13] D. Kirshen, G. Strbac, "Fundamentals of power systems economics", $1^{\text {st }}$ edition, John Wiley \& Sons, 2005.

[14] T. Zhao, X. Pan, S. Yao, P. Wang, "Stackelberg game based energy and reserve management for a fast electric vehicle charging station", Energy Conversion Congress and Exposition (ECCE), Cincinnati, OH, UnitedStates, October 2017.
[15] H. Wu, M. Shahidehpour, A. Alabdulwahab, A. Abusorrah, "A game theoretic approach to risk-based optimal bidding strategies for electric vehicle aggregators in electricity markets with variable wind energy resources", IEEE Transactions on Sustainable Energy, Vol. 7, No 1, pp 374-385, 2016.

[16] A. De Paola, D. Angel, G. Strbac, "Price-based schemes for distributed coordination of flexible demand in the electricity market", IEEE Transactions on Smart Grid, Vol. 8, No 6, pp 3104-3116, 2017.

[17] P. Vytelingum, T. D. Voice, S.D. Ramchurn, A. Rogers, N. R. Jennings "Agent-based micro-storage management for the smart grid", Proceedings of the 9th International Conference on Autonomous Agents and Multiagent Systems, Vol. 1, pp 39-46, Toronto, Canada, May 2010.

[18] J. Cludius, H. Hermann, F. C. Matthes, V. Graichen, "The merit order effect of wind and photovoltaic electricity generation in Germany 2008 2016: Estimation and distributional implications", Energy Economics, Vol. 44, pp 302-313, 2014.

[19] M. Carrión, J. M. Arroyo, “A computationally efficient mixed-integer linear formulation for the thermal unit commitment problem", IEEE Trans. On Power Systems, vol 21, no 3, pp 1371-1378, 2006.

[20] H. Farahmand, G. L. Doorman, "Balancing market integration in the Northen European continent", Applied Energy, Vol. 96, pp 316-326, 2012.

[21] J. Lofberg, "YALMIP: a toolbox for modelling and optimization in MATLAB”, IEEE International Symposium on Computer Aided Control Systems Design, New-Orleans, USA, pp. 282-289, 2004.

[22] F. Musgens, A. Ockenfels, M. Peek, "Economics and design of balacing power markets in Germany", Electrical Power and Energy Systems, Vol. 55, pp 392-401, 2014.

[23] B. Burghozer, T. Wien, "Evaluation of different balancing market designs with the EDisOn+Balancing model", $13^{\text {th }}$ International Conference on European Energy Market (EMM), Porto, Portugal, 2016.

[24] H. Pandžić, Y. Wang, T. Qiu, Y. Dvorkin, D. S. Kirschen, "Near-optimal method for siting and sizing of distributed storage in a transmission network", IEEE Transactions on Power Systems, vol. 25, no. 1, pp. 2288 $2300,2015$.

[25] Y. G. Park, C. W. Kim, J. B. Park, "MILP-based dynamic efficiency scheduling model of battery energy storage systems", Journal of Electrical Engineering and Technology, Vol. 11, pp 1921-1927, 2016.

[26] California Independent System Operator, "What the duck curve tells us about managing a green grid", [online] www.caiso.com

[27] M.T. Kuo, S. D. Lu, M. C. Tsou, "Considering carbon emissions in economic dispatch", IEEE Transactions on Industry Applications, Vol. 54, No. 2, pp. 987-997, 2018.

[28] Y. Zhang, F. Yao, H. H.C. Iu, T. Fernando, H. Trinh, "Wind-thermal systems operation optimization considering emission problem", Electrical Power and energy Systems, Vol. 65, pp. 238-245, 2015.

[29] R. Turconi, A. Boldrin, T. Astrup, "Life cycleassessment (LCA) of electricity generation technologies: overview, comparability and limitations", Renewable and Sustainable Energy Reviews, Vol. 28, pp. 555-565, 2013.

[30] J. Stich, M. Mannhart, T. Zipperle, T. Massier, M. Huber, T. Hamacher, "Modelling a low-carbon power system for Indonesia, Malaysia and Singapore", $33^{\text {rd }}$ IEW International Energy Workshop, Beijing, China, 2014.

[31] IEA Statistics, OECD/IEA, 2014 [online] www.iea.org/stats/index.asp 